\title{
Managing dyspnea in pregnancy-an errand uphill: an experience from the critical care obstetric unit of a tertiary care facility in India
}

\author{
Sheeba Marwah ${ }^{1 *}$, Jyotsana $\mathrm{Suri}^{2}$, Pratima Mittal ${ }^{2}$ \\ ${ }^{1}$ Department of Obstetrics and Gynecology, NDMC Medical College and Hindu Rao Hospital, New Delhi, India \\ ${ }^{2}$ Department of Obstetrics and Gynecology, VMMC and Safdarjung Hospital, New Delhi, India
}

Received: 28 November 2017

Accepted: 18 December 2017

*Correspondence:

Dr. Sheeba Marwah,

E-mail: sheebamarwah@yahoo.co.in

Copyright: ( $\odot$ the author(s), publisher and licensee Medip Academy. This is an open-access article distributed under the terms of the Creative Commons Attribution Non-Commercial License, which permits unrestricted non-commercial use, distribution, and reproduction in any medium, provided the original work is properly cited.

\section{ABSTRACT}

Background: The occurrence of dyspnea in a gravid woman induces the query in the treating obstetrician regarding its root cause being either underlying or new cardiac or pulmonary disease, or due to the pregnancy itself. Attainment to this conclusion requires grasp of the cardiopulmonary changes befalling during normal pregnancy, as well as detection of the ailment of dyspnea during antenatal period. Objective of present study was to find out the incidence and feto-maternal outcome of patients presenting with dyspnea in pregnancy and puerperium.

Methods: This study was conducted in Department of Obstetrics and Gynaecology in Vardhaman Mahavir Medical College and Safdarjung hospital over a period of one year, wherein review of all women who had presented with a diagnosis of dyspnea in pregnancy and puerperium, and admitted and treated in the Critical care obstetric unit of the department was done. Thorough evaluation was done and case files were exhaustively reviewed, data was anonymously extracted, and outcomes analyzed. All causes of mortality were also recorded. The primary outcome was incidence of dyspnea in pregnancy. Secondary outcomes measured were socio-demographic variables, timing of presentation-antepartum=first trimester, second trimester, third trimester/postpartum $<48$ hours, 3-7 days, $>7$ days, causative factors for dyspnea, any other obstetric complications, mode of delivery, fetal outcome (fetus weight, Apgar score, need for NICU admission), need for ICU/HDU admission, duration and course in the hospital, mortality, and cause of death in case of mortality. Data recording was done on a predesigned proforma and deciphered at the end of study and analyzed.

Results: Incidence of dyspnea was $1.97 \%$ of all admissions. Pulmonary edema following hypertensive disorders of pregnancy, was the leading cause. $28.5 \%$ women succumbed to their illness. Majority were preterm births (88/112), requiring NICU admission.

Conclusions: The clinician should be able to determine the underlying cause of dyspnea, differentiating it from physiologic progesterone-induced hyperventilation. Strategy of expeditious delivery during the third trimester is often warranted after weighing fetal outcome and maternal risk in such women.

Keywords: Dyspnea, Causes, Feto-maternal outcome, Pregnancy

\section{INTRODUCTION}

Dyspnea or shortness of breath or difficult, labored, consciousness about taking breath is a common symptom during pregnancy that makes even simple everyday activities a major challenge. ${ }^{1}$ Around $50 \%$ of gravidas, even without history of cardiac or pulmonary disease, experience it sometime during their gestation. ${ }^{1}$ These symptoms may be related to physiological changes in cardio-pulmonary, hematopoietic system, increase in 
weight etc. that occur during pregnancy. ${ }^{2-4}$ Also, pregnancy has been identified as a stressor to the cardiovascular and the respiratory systems. ${ }^{5}$ Any amount of breathing difficulties during gestation may indicate a decompensation.

Assessment, resuscitation and management of the critically ill obstetric patient with respiratory compromise presents a unique clinical challenge to the obstetricians. ${ }^{1,5}$ This is chiefly attributed to maternal physiological adaptations, some pregnancy specific conditions requiring critical care management, and presence of a fetus whose well-being is linked to the mother. ${ }^{5}$ Successful feto-maternal outcomes in such patients contemplate a multidisciplinary approach in liaison with a pulmonologist, cardiologist, intensivist, and neonatologist ,besides the obstetrician. ${ }^{6}$

Due to varied etiology and lack of sufficient research on such patients, especially in LMIC countries, optimal management of women presenting with dyspnea in pregnancy remains elusive. ${ }^{1-11}$

Keeping this in mind, the present research is conceived to find out the etiology and outcome of patients presenting with dyspnea in obstetric emergency. This would be in turn instrumental in formulating institutional guidelines for management of such women, which could be widely applied across nation.

\section{METHODS}

The present study was conducted in Department of Obstetrics and Gynaecology in Vardhaman Mahavir Medical College and Safdarjung hospital over a period of one year from March 2016 to February 2017, wherein review of all patients who had presented with a diagnosis of dyspnea in pregnancy and puerperium, and admitted and treated in the Critical care obstetric unit of the department was done.

Their case files were thoroughly reviewed, and data was anonymously extracted and outcomes analyzed.

All causes of mortality were also recorded. The primary outcome was incidence of dyspnea in pregnancy. Secondary outcomes measured were socio-demographic variables, timing of presentation-antepartum=first trimester, second trimester, third trimester/postpartum $<48$ hours, 3-7 days, $>7$ days, causative factors for dyspnea, any other obstetric complications, mode of delivery, fetal outcome (fetus weight, Apgar score, need for NICU admission), need for ICU/HDU admission, duration and course in the hospital, mortality, and cause of death in case of mortality.

Data recording was done on a predesigned proforma and deciphered at the end of study, and analyzed.

\section{RESULTS}

During the study period, total number of obstetric admissions were 8501, and 27222 deliveries. Amongst these, 168 number of cases presented with dyspnea in pregnancy or puerperium, the incidence being $1.97 \%$ of all admissions. However out of the 825 admissions during the same period in the obstetric ICU (CCOB), these cases constituted $20.36 \%$.

Table 1: Demographic and maternal characteristics.

\begin{tabular}{|c|c|c|c|}
\hline $\begin{array}{l}\text { Baseline } \\
\text { characteristics }\end{array}$ & $\begin{array}{l}\text { Cases } \\
n=168(\%)\end{array}$ & Percentage & P value \\
\hline \multicolumn{4}{|l|}{ Age (years) } \\
\hline$<20$ & 0 & 0 & \multirow{4}{*}{$<.0001$} \\
\hline $20-25$ & 96 & 57.14 & \\
\hline $25-30$ & 48 & 28.57 & \\
\hline$>30$ & 24 & 14.29 & \\
\hline \multicolumn{4}{|l|}{ Parity } \\
\hline Primigravida & 72 & 42.86 & \multirow{3}{*}{$<.0001$} \\
\hline G2-G4 & 72 & 42.86 & \\
\hline$>\mathrm{G} 5$ & 24 & 14.29 & \\
\hline \multicolumn{4}{|l|}{ Religion } \\
\hline Hindu & 120 & 71.43 & \multirow{5}{*}{$<0.0001$} \\
\hline Muslim & 44 & 26.19 & \\
\hline Sikh & 4 & 2.38 & \\
\hline Christian & 0 & 0 & \\
\hline Others & 0 & 0 & \\
\hline \multicolumn{4}{|c|}{ SE status (Modified Kuppuswami) } \\
\hline Upper & 0 & 0 & \multirow{5}{*}{$<0.0001$} \\
\hline Upper middle & 0 & 0 & \\
\hline Lower middle & 24 & 14.29 & \\
\hline Upper Lower & 24 & 14.29 & \\
\hline Lower & 72 & 42.86 & \\
\hline \multicolumn{4}{|l|}{ Residence } \\
\hline $\begin{array}{l}\text { Urban } \\
\text { Rural }\end{array}$ & 168 & 100 & - \\
\hline \multicolumn{4}{|l|}{ Booking status } \\
\hline Referred & 159 & 94.64 & $<0.0001$ \\
\hline Booked & 9 & 5.36 & \\
\hline \multicolumn{4}{|l|}{ BMI } \\
\hline$<18$ & 24 & 14.29 & \multirow{4}{*}{$<0.0001$} \\
\hline $18-24.9$ & 96 & 57.14 & \\
\hline $25-29.9$ & 36 & 21.43 & \\
\hline$>30$ & 12 & 7.14 & \\
\hline
\end{tabular}

Preponderance of women was seen between 20-30 years (significantly higher than other age group), with mean age being $24.09 \pm 5.1$ years. Maximum women were multigravidas. All of the patients were un-booked, having no or inadequate antenatal supervision, being referred from peripheral hospitals (Table 1).

Ninety six women presented during antenatal period, whereas in the remaining 72 women, 60 presented within first 24 hours, whilst rest within 7 days of delivery or miscarriage. 
Table 2: Distribution of subjects according to timing of presentation in pregnancy, and delivery details of the women.

\begin{tabular}{|c|c|c|c|c|}
\hline & $\begin{array}{l}\text { Cases } \\
(n=168)\end{array}$ & $\%$ & $\begin{array}{l}P \\
\text { value }\end{array}$ & $\begin{array}{l}P \\
\text { value }\end{array}$ \\
\hline Postpartum & 72 & 42.86 & \multirow{4}{*}{$<0.0001$} & \multirow{4}{*}{0.064} \\
\hline$<48 \mathrm{hrs}$ & 60 & 35.71 & & \\
\hline 3-7days & 12 & 7.14 & & \\
\hline $2^{\text {nd }}-6^{\text {th }}$ week & 0 & 0 & & \\
\hline Antepartum & 96 & 57.14 & & \\
\hline $1^{\text {st }}$ trimester & 7 & 4.17 & \multirow{3}{*}{$<0.0001$} & \\
\hline $2^{\text {nd }}$ Trimester & 40 & 23.81 & & \\
\hline Third trimester & 49 & 29.17 & & \\
\hline \multicolumn{3}{|l|}{ Delivery status } & & \\
\hline Undelivered & 4 & 2.38 & \multirow{2}{*}{$<0.0001$} & \\
\hline Delivered & 164 & 97.62 & & \\
\hline \multicolumn{3}{|c|}{ Mode of delivery } & \multirow{5}{*}{$<0.0001$} & \\
\hline $\mathrm{D} / \mathrm{C}$ & 16 & 9.52 & & \\
\hline Vaginal & 33 & 19.64 & & \\
\hline $\begin{array}{l}\text { Operative vaginal } \\
\text { delivery }\end{array}$ & 7 & 4.17 & & \\
\hline Caesarean section & 112 & 66.67 & & \\
\hline \multicolumn{3}{|c|}{ Place of delivery } & \multirow{4}{*}{$<0.0001$} & \\
\hline Present Facility & 92 & 54.76 & & \\
\hline Home & 24 & 14.29 & & \\
\hline Other hospital & 48 & 28.57 & & \\
\hline
\end{tabular}

Out of the 96 women, only four pts remained undelivered, the difference being statistically significant. However, there was no significant difference in distribution of timing of presentation i.e. antepartum and postpartum. Amongst those presenting prenatally, second and third trimester patients were significantly higher than first trimester (Table 2).

Analyzing the causes, pulmonary edema following hypertensive disorders of pregnancy, emerged as the leading cause.

Congestive heart failure in the setting of severe anemia was a close second $(21.43 \%)$. Cardiac diseases and Infectious etiology were seen in $16.67 \%$ of women each (Table 3).

Majority (80\%) women were admitted in critical condition. Despite best efforts, $28.5 \%$ women succumbed to their illness, most common cause of death being cardiac disease $(41.67 \%)$, $p$ value $<0.001$, followed by pulmonary edema. Apart from the four women who died undelivered, live born babies were delivered by 112 women. Out of these, majority were preterm (88/112), requiring NICU admission. Fifty six infants had an early neonatal death (Table 4).

Table 3: Causes of dyspnea.

\begin{tabular}{|c|c|c|c|c|}
\hline Causes of dyspnea & Cases & $\%$ & P value & P value \\
\hline CHF due to severe anemia with & 36 & 21.43 & & \\
\hline Incomplete abortion & 9 & 5.36 & \multirow{3}{*}{0.472} & \multirow{20}{*}{$<0.0001$} \\
\hline APH & 12 & 7.14 & & \\
\hline $\mathrm{PPH}$ & 15 & 8.93 & & \\
\hline Pulmonary edema with hypertensive disorder of pregnancy & 64 & 38.10 & \multirow{5}{*}{$<0.0001$} & \\
\hline Severe preeclampsia & 47 & 27.98 & & \\
\hline Antepartum eclampsia & 7 & 4.17 & & \\
\hline Chronic hypertension with superimposed preeclampsia & 6 & 3.57 & & \\
\hline HELLP & 4 & 2.38 & & \\
\hline Failure due to cardiac disease & 28 & 16.67 & & \\
\hline RHD without PAH & 12 & 7.14 & \multirow{3}{*}{0.368} & \\
\hline RHD with PAH & 6 & 3.57 & & \\
\hline CHD & 10 & 5.95 & & \\
\hline$\sim \mathrm{ASD}$ & 7 & 4.17 & \multirow{2}{*}{0.206} & \\
\hline$\sim$ Situs inversus + dextrocardia & 3 & 1.79 & & \\
\hline Infectious etiology & 28 & 16.67 & & \\
\hline Tuberculosis & 10 & 5.95 & \multirow{4}{*}{0.099} & \\
\hline Asthma & 6 & 3.57 & & \\
\hline Pneumothorax & 2 & 1.19 & & \\
\hline $\mathrm{H} 1 \mathrm{~N} 1$ & 10 & 5.95 & & \\
\hline ARDS in setting of MODS & 12 & 7.14 & - & \\
\hline
\end{tabular}

All the women were admitted in obstetric HDU for management. Maximum women required intensive resuscitative procedures including intubation (152) and use of vasopressors (112). Eight women required 
evacuation for incomplete abortion, while 16 were taken up for urgent laparotomy and further procedure (Table 5).

Table 4: Hospital course.

\begin{tabular}{|c|c|c|c|}
\hline Hospital course & $\begin{array}{l}\text { Cases, } \\
\mathrm{N}=168\end{array}$ & $\%$ & P value \\
\hline \multicolumn{4}{|c|}{ Condition on admission } \\
\hline Critical & 136 & 80.95 & \multirow{3}{*}{$<0.0001$} \\
\hline $\begin{array}{l}\text { Sick but not } \\
\text { critical }\end{array}$ & 28 & 16.67 & \\
\hline Stable & 4 & 2.38 & \\
\hline \multicolumn{4}{|l|}{ Maternal outcome } \\
\hline Died & 48 & 28.57 & \multirow{3}{*}{$<0.0001$} \\
\hline Recovered & 120 & 71.43 & \\
\hline LAMA & 0 & 0 & \\
\hline \multicolumn{4}{|c|}{ Underlying cause of death, $n=48$} \\
\hline MODS & 7 & 14.58 & \multirow{4}{*}{0.020} \\
\hline $\begin{array}{l}\text { Severe anemia in } \\
\text { failure }\end{array}$ & 7 & 14.58 & \\
\hline HDP & 14 & 29.17 & \\
\hline Cardiac disease & 20 & 41.66 & \\
\hline \multicolumn{4}{|l|}{ Hospital Stay } \\
\hline$<6 \mathrm{hrs}$ & 24 & 14.29 & \multirow{5}{*}{$<0.0001$} \\
\hline $6-24 \mathrm{hrs}$ & 9 & 5.36 & \\
\hline $24-48 \mathrm{hrs}$ & 9 & 5.36 & \\
\hline 2-7 days & 78 & 46.43 & \\
\hline$>7$ days & 48 & 28.57 & \\
\hline \multicolumn{4}{|c|}{ Fetal outcome $(n=164)$} \\
\hline $\mathrm{D} / \mathrm{C}$ & 16 & 9.76 & $<0.0001$ \\
\hline Still born & 40 & 24.39 & $<0.0001$ \\
\hline Live born & 112 & 68.29 & $<0.0001$ \\
\hline Preterm & 88 & 53.66 & $<0.0001$ \\
\hline Term & 24 & 14.63 & $<0.0001$ \\
\hline NICU & 88 & 53.66 & $<0.0001$ \\
\hline NND & 56 & 34.15 & 1.00 \\
\hline
\end{tabular}

Table 5: Interventions done.

\begin{tabular}{|lll|}
\hline $\begin{array}{l}\text { Intervention } \\
\text { HDU admission requiring } \\
\text { resuscitative (CAB) or cardio } \\
\text { respiratory support }\end{array}$ & 168 & 100 \\
\hline $\begin{array}{l}\text { Resuscitative } \\
\text { procedures/intubation } \\
\text { mechanical ventilation }\end{array}$ & 152 & 90.48 \\
\hline $\begin{array}{l}\text { Use of cardiotonics/ vasopressors/ } \\
\text { digitalization }\end{array}$ & 112 & 66.67 \\
\hline $\begin{array}{l}\text { Evacuation } \\
\text { Laparotomy with procedures }\end{array}$ & 8 & 4.76 \\
\hline Anticoagulant therapy & 48 & 9.52 \\
\hline
\end{tabular}

Amongst the preventable modifiable factors, considerable delay in women seeking help (39\%), delay in diagnosis and lack of recognition of gravity of ailment (36\%) and in deferment in referral of patient to tertiary care hospital $(33 \%)$ were the principal amendable causative aspects that were divulged during the analysis that were associated with dyspnea in pregnancy (Table 6).
Table 6: Modifiable factors/ delays.

\begin{tabular}{|c|c|c|}
\hline Delays & Cases \% & P value \\
\hline Personal/family & $148 \quad 88.09$ & $<0.0001$ \\
\hline $\begin{array}{l}\text { Delay in woman seeking } \\
\text { help }\end{array}$ & 128 & $<0.0001$ \\
\hline \multicolumn{3}{|l|}{ If yes, why - } \\
\hline Lack of awareness & 109 & \multirow{4}{*}{$<0.0001$} \\
\hline Lack of resources & 10 & \\
\hline Past adverse experience & 0 & \\
\hline $\begin{array}{l}\text { Refusal of } \\
\text { treatment/admission }\end{array}$ & 9 & \\
\hline \multicolumn{3}{|l|}{ Logistics } \\
\hline $\begin{array}{l}\text { Lack of adequate transport } \\
\text { from home to health care } \\
\text { facility }\end{array}$ & 20 & $<0.0001$ \\
\hline $\begin{array}{l}\text { Lack of transport between } \\
\text { health facilities }\end{array}$ & 64 & 0.005 \\
\hline $\begin{array}{l}\text { Lack of communication } \\
\text { network }\end{array}$ & 48 & $<0.0001$ \\
\hline \multicolumn{3}{|l|}{ Referral facilities } \\
\hline Infrastructural issues & 40 & $<0.0001$ \\
\hline $\begin{array}{l}\text { Lack of } \\
\text { medications/instruments/ } \\
\text { Equipment/consumables }\end{array}$ & 28 & $<0.0001$ \\
\hline $\begin{array}{l}\text { Non utilization of available } \\
\text { medications/instruments/ } \\
\text { equipments/consumables }\end{array}$ & 0 & - \\
\hline $\begin{array}{l}\text { Lack of blood /blood } \\
\text { products }\end{array}$ & 24 & $<0.0001$ \\
\hline Lack of expertise & 24 & $<0.0001$ \\
\hline \multicolumn{3}{|l|}{ Present facility/facilities } \\
\hline $\begin{array}{l}\text { Infrastructural issues (lack } \\
\text { of available ICU bed) }\end{array}$ & 4 & $<0.0001$ \\
\hline $\begin{array}{l}\text { Lack of } \\
\text { medications/instruments, } \\
\text { equipments/consumables }\end{array}$ & 0 & - \\
\hline $\begin{array}{l}\text { Non utilization of } \\
\text { available medications, } \\
\text { instruments, } \\
\text { equipments/consumables }\end{array}$ & 0 & - \\
\hline $\begin{array}{l}\text { Lack of blood /blood } \\
\text { products }\end{array}$ & 0 & - \\
\hline
\end{tabular}

\section{DISCUSSION}

Dyspnea is a highly threatening experience of breathlessness experienced by around 60-70\% pregnant patients due to diverse pathologies, including respiratory, cardiovascular disorder. Despite optimization of diseasespecific treatments, it is often insufficiently treated. ${ }^{1,7}$ The enormous burden met by such women, their families and the healthcare system, makes improving management of dyspnea a priority in developing countries like India. Though a few studies are available depicting outcome of ARDS in pregnancy, the paucity of research articles scrutinizing the causes, and outcome of dyspnea in pregnancy remains the strongest forte of this study. ${ }^{7-13}$ 
In the course of the study period of one year, $1.9 \%$ of the total admissions (17002) in obstetrics and gynecology department presented with dyspnea. This was quite a high incidence.

In contrast with previous literary work, a relatively younger woman in the present study emulates an early age at marriage and childbearing in India. ${ }^{1-12}$ On further analysis, most of them were un-booked with no prior antenatal supervision, belonging to lower socioeconomic background. Maximum females thus came as referral cases from peripheral centers drained by our hospital, following lack of awareness about the entity or unsatisfactory and inadequate treatment practices by less skilled practitioners available there.

In under-resourced backdrops like in rural India, it becomes an imperative requisite to segregate the unbooked / referred cases presenting to a health facility from those acquiring the clinical entity in the hospital setting itself; since the former is symbolic of a deficient infrastructure, or failure in access to the available health amenities in the peripheral units and/or to the referral chain. It also emphasizes that such first referral units should be made armed with plenteous capital and resources, besides sufficient health workers proficient in handling such emergencies.

These aforementioned observations were in consonance with the available reviews in literature across the world, again reiterating that this cohort of women bears most of the predisposing co-morbidities. ${ }^{7-13}$ It may be further ascribed to poverty, illiteracy, malnutrition, early age at marriage and subsequently initial conception. This legion of women is often oblivious of the essential and emergent obstetric services, need for prenatal care, symptoms and concept of high risk pregnancy. Besides, per se, they are clinically underfed, with concomitant comorbidities like tuberculosis and anemia, as was found in the present study.

Analogous to the biochemical and mechanical changes during gestation, usually, the symptom of dyspnea starts during the first or second trimester; the frequency then rises during the second trimester, and becomes reasonably stable during the third trimester. ${ }^{14-16}$ But in the extant study, maximum women (49/96) presenting in antenatal period were term/ near term. This could be attributed to the underlying causes, mostly hypertensive disorders and cardiac causes, where women decompensated after end of second trimester, simulating the physiology of pregnancy.

In parallel to previous reviews available, pulmonary edema following hypertensive disorders of pregnancy, appeared as the foremost cause in study population. ${ }^{7-11}$ Literature says that rise in hydrostatic pressure from hypertension and alterations in capillary membrane permeability results in pulmonary edema in around 3\% of women with preeclampsia/ eclampsia, typically after delivery, when plasma oncotic pressure is at its lowest. ${ }^{7,14-16}$ Similar to this, maximum women $(70 \%)$ presented post-partum with shortness of breath in the present study too, majority within first 24 hours. Older and multiparous women are at the greatest risk for pulmonary edema. Since full blown pulmonary edema is often accompanied by dysfunction of another organ system, like disseminated intravascular coagulation, acute renal failure, hypertensive crisis, cardiopulmonary arrest, or cerebral edema, it becomes imperative on the part of the obstetrician to have a high index of suspicion and prompt diagnosis and adept management strategies in their clinical armamentarium. Earliest hunch for development of this symptom should prompt speedy referral to a tertiary care infirmary with dedicated obstetric ICU for multidisciplinary management.

Anemia leading to congestive failure continues to be a main causative factor for dyspnea in Indian setting. This sadly reflects poor maternal health services in the borough, including dearth of cognizance, accessibility, availability and ignorance on the part of the patients. Alas, it also indicates the failure of the health system to decrease anemia in reproductive population, till date, despite best efforts and national policies. It also provides the health care providers with an opportunity to re-look into the prevalence, causes of anemia in Indian females, and to rectify and formulate novel strategies to combat this comorbidity at an early stage, to thwart its devastating complications during pregnancy, depriving mother of a safe motherhood and healthy baby.

The extant study also witnessed high incidence of cardiac etiology as the plausible causative factors instrumental in dyspnea in women. This was equivalent to conclusions of former canvassers from developing countries, who have shown a rise in cardiac diseases in pregnancy over the time owing to better diagnosis and newfangled treatments..$^{17-18}$

Around $\sim 7.14 \%$ of women had dyspnea following multiorgan failure; this signifies the need of a prompt and thorough evaluation for impending sepsis in pregnant women at the slightest of suspicion, which would be a constructive step in averting end organ damage and curtailing sepsis related morbidity and mortality in the country. It also supports maintenance of hygiene and asepsis by doctors and midwifery, besides upgrading of their knowledge up-to-date with new-fangled protocols in infection control in pregnant population. ${ }^{19}$

Unlike the western literature, very few women had asthma exacerbations during their pregnancy. ${ }^{20-23}$ This can be ascribed to the largely rural population coming to the hospital for their antenatal care. However, this cohort of women was largely predisposed to acquiring pneumonia and infectious diseases including tuberculosis.

Around eighty percent women were already critical when admitted highlights the significance of early diagnosis 
and referral. The high rate of mortality (28.5\%), when contrasted with previous researchers, could be accredited to considerable delay in diagnosis of same by index physician, non-recognition of severity of disease by the primary caregiver and tardy referral to tertiary care hospital. ${ }^{7-12}$ Besides, Safdarjung hospital, being one of the largest tertiary care hospitals of India, serves to a substantial amount of gravely sick referred cases from adjacent states of North India. Typical hitches associated with dearth of skilled experts, incorrect prescriptions, non/hardly operational laboratory facilities at the smaller peripheral hospices were also influential in the same.

Early multidisciplinary consultation is essential to optimize maternal and fetal outcomes. Maternal-fetal medicine, neonatology, anesthesiology, and intensivist clinicians should all be engaged in proposing appropriate timing, location, and mode of delivery. Also required surgical provisions and neonatal resuscitation facilities should also be readily available with minimal delay.

Apart from the four women who died undelivered, all remaining were delivered, either by abdominal/vaginal delivery, mostly preterm, as per the hospital protocol after meticulously weighing gestational age of the fetus, fetal status, maternal risk, and the gestational age at which the treating institution can support a preterm infant.

The alleged clarification behind this is relief of aortocaval compression and improvement in maternal cardiac output following evacuation of the gravid uterus. ${ }^{18,19}$ This was in consonance of the findings of few past pollsters who have suggested that delivery may improve maternal status in ventilated women, and some authors have suggested elective delivery for women in late pregnancy who have ARDS but are clinically stable $(5,94)$. However, others have stated that given the risks of inducing labor or performing a cesarean, the indications for delivery in such women should be obstetric. ${ }^{1,7-11}$

Little literature exists to guide the decisions on the mode of delivery. The final choice should again be based on standard obstetric indications for cesarean delivery, and attempts should be made to optimize maternal oxygenation and pain control during vaginal deliveries $7,8,11$. Also, in the event of maternal cardiopulmonary arrest, perimortem cesearean cesarean delivery is recommended within 4 mins for the benefit of both the mother and the fetus, without documentation of fetal status

All the women were admitted in obstetric HDU for management. Maximum women required intensive resuscitative procedures including intubation (152) and use of vasopressors (112). The decision about whether to intubate a patient should be taken considering the fact that these women have hypocapnia due to hyperventilation at baseline. Intubation was often difficult during pregnancy and the peripartum period due to upper airway edema and diminished airway caliber, especially late in pregnancy. Once the patient had been stabilized and the cause of the acute respiratory failure was determined, ongoing management included supportive care and treatment of the etiology, as per the reviews. ${ }^{1}$

The conclusions drawn stressed that most of the women in the study were unaware of the gravity of symptoms of dyspnea and its associated causes, seeking help late, often when the entity had been fully established or worsened with complications. This reiterates that heath education, promotion and mass communication becomes the need of the hour, especially for obstetric population. Besides clinicians at the local peripheral hospitals, including midwives must be made versed with the concept of high risk pregnancy, enlightened about early identification and diagnosis of common problems like preeclampsia, heart disease, in order to refer women in time after initial resuscitation.

Our corollaries, having been elicited from a relatively smaller study population, cannot be an accurate representation of respiratory distress at the national level. Also, this being a single centered hospital based study, it cannot reverberate data countrywide, and as morbidity and mortality occurring in community due to same would still be missing.

\section{CONCLUSION}

Dyspnea is a common symptom in pregnancy. An early diagnosis along-with intensive care resourcing influences the efficacy of goal-directed therapy. Strategy of expeditious delivery during the third trimester often warranted after weighing fetal outcome, maternal risk. Multidisciplinary approach and dedicated CCOB-long way in preventing morbidity and mortality. However, Under-reporting of cases leads to underestimation of its contribution to maternal death.

On the whole, most of the serious snags of this otherwise common symptom in pregnancy can be circumvented by enhancing health education, disseminating consciousness among antenatal females and equipping the trivial health units also with best amenities to tackle obstetric emergencies care, above and beyond, boosting the manpower at the first referral units.

\section{ACKNOWLEDGMENTS}

Authors render earnest thankfulness to all patients (and their relatives) in this study, for their kind cooperation and patience exhibited during the study.

Funding: No funding sources

Conflict of interest: None declared

Ethical approval: The study was approved by the Institutional Ethics Committee 


\section{REFERENCES}

1. Lee SY, Chien DK, Huang CH, Shih SC, Lee WC. Dyspnea in pregnancy. Taiwanese J Obstet Gynecol. 2017;56:432-6.

2. Graves CR. Acute pulmonary complications during pregnancy. Clin Obstet Gynecol. 2002;45(2):369-76.

3. Mighty HE. Acute respiratory failure in pregnancy. Clin Obstet Gynecol. 2010;53(2):360-8.

4. Pandey D, Garg D, Tripathi BN, Pandey S. Dyspnea in pregnancy: an unusual cause. J Basic Clin Reprod Sci. 2014;3(1):68-70.

5. Mu Y, Mcdonnel N, Li Z, Liang J, Wang Y, Zhu J, et al. Amniotic fluid embolism as a cause of maternal mortality in China between 1996 and 2013: a population-based retrospective study. BMC Pregnancy Childbirth. 2016;16:316.

6. Hayen A, Herigstad M, Pattinson KTS. Understanding dyspnea as a complex individual experience. Maturitas. 2013;76:45-50.

7. Rush B, Martinka P, Kilb B, McDermid RC, Boyd $\mathrm{JH}$, Celi LA. Acute respiratory distress syndrome in pregnant women. Obstet Gynecol. 2017;129(3):5305.

8. Catanzarite V, Willms D, Wong D, Landers C, Cousins L, Schrimmer D. Acute respiratory distress syndrome in pregnancy and the puerperium: causes, courses, and outcomes. Obstet Gynecol. 2001;97:760-4.

9. Mabie WC, Barton JR, Sibai BM. Adult respiratory distress syndrome in pregnancy. Am J Obstet Gynecol. 1992;167:950-7.

10. Schwaiberger D, Karcz M, Menk M, Papadakos PJ, Dantoni SE. Respiratory failure, and mechanical ventilation in the pregnant patient. Crit Care Clin. 2016; 32:85-95.

11. Catanzarite VA, Willms D. Adult respiratory distress syndrome in pregnancy: report of three cases and review of the literature. Obstet Gynecol Surv. 1997;52:381-92.

12. ANZIC Influenza Investigators and Australasian Maternity Outcomes Surveillance System. Critical illness due to $2009 \mathrm{~A} / \mathrm{H} 1 \mathrm{~N} 1$ influenza in pregnant and postpartum women: population based cohort study. BMJ 2010;340:c1279.
13. Cole DE, Taylor TL, McCullough DM, Shoff CT, Derdak S. Acute respiratory distress syndrome in pregnancy. Crit Care Med. 2005;33(suppl):S269-78.

14. Cugell DW, Frank NR, Gaensler EA, Badger TL. Pulmonary function in pregnancy. I. Serial observations in pregnant women. Am Rev Tuberc. 1953;67:568-97.

15. Knuttgen HG, Emerson K Jr. Physiological response to pregnancy at rest and during exercise. J Appl Physiol. 1974;36:549-53.

16. Liberatore SM, Pistelli R, Patalano F, Moneta E, Incalzi RA, Ciappi G. Respiratory function during pregnancy. Respiration. 1984;46:145-50.

17. El-Khayam U, Gleicher N. Cardiac evaluation during pregnancy. In: Elkhayam U, Gleicher $\mathrm{N}$ (eds) Cardiac problems in pregnancy, $3^{\text {rd }}$ ed. Wiley-Liss, New York;1998.

18. Marwah S, Sharma M, Gaikwad H, Mohindra R. Cardiac disease in pregnancy: still an arduous conundrum for the obstetrician. Int $\mathbf{J}$ Reprod Contracept Obstet Gynecol. 2016; 5:1292-9

19. Marwah S, Topden SR, Sharma M, Mohindra R. Severe Puerperal Sepsis-A simmering menace. J Clin Diagn Res. 2017;11(5):QC04-QC08.

20. Weinberger SE, Weiss ST, Cohen WR. Pregnancy and the lung: state of the art. Am Rev Repsir Dis. 1980;121:559-81.

21. Gilroy RJ, Mangura BT, Lavietes MH. Rib cage and abdominal volume displacements during breathing in pregnancy. Am Rev Respir Dis. 1988;137:668-72.

22. Stenius-Aarniala B, Riikonen S, Teramo K. Asthma and pregnancy: a prospective study of 198 pregnancies. Thorax. 1988;43:12-18.

23. Schatz M, Harden K, Forsythe A, Chilingar L, Hoffman C, Sperling W et al. The course of asthma during pregnancy, post-partum, and with successive pregnancies: a prospective analysis. J All Clin Immunol. 1988;81:509-17.

Cite this article as: Marwah S, SuriJ, Mittal P.

Managing dyspnea in pregnancy-an errand uphill: an experience from the critical care obstetric unit of a tertiary care facility in India. Int J Reprod Contracept Obstet Gynecol 2018;7:152-8. 